\title{
Estágio como fonte de conhecimento ou mão-de-obra menos onerosa?
}

\begin{abstract}
Elisete Dahmer Pfischer
Doutora em Engenharia da Produção e professora na Universidade Federal de Santa Catarina - UFSC pdahmer@bol.com.br

Joisse Antônio Lorardi Mestre em Ciências Contábeis e professora na UFȘC lorandi@cse.ufsc.br

Sérgio Marian Mestrando em Contabilidade smarian@cse.ufsc.br

Leticia Fátima Nascimento Acadêmica do curso de Ciências Contábeis da UFSC seisdejulho@pop.com.br

Paulo César Pfischer Acadêmico do curso de Ciências Contábeis da UFSC pdahmer@uol.com.br

Michely Nascimento Acadêmica do curso de Ciências Contábeis da UFSC michelydi@hotmail.com
\end{abstract}

Resumo

A interação entre a gestäo de conhecimento e os estágios leva a uma avaliação dos procedimentos adotados pelas empresas concedentes. Os estagiários, por sua vez, esperam obter benefícios de ensino e aprendizagem, como também econômicos. Estes últimos na maioria das vezes ocorrem para subsidiar as despesas advindas da sua permanência na universidade. Contudo, quando iniciam a tão almejada etapa de 
estágio, normalmente a partir da $5^{\circ}$ fase, se deparam com uma realidade näo esperada. Alguns são utilizados como substitutos de outros funcionários, servindo assim como "mão-de-obra barata," pela não incidência dos encargos sociais. Notifica-

se, entretanto, que a aplicação dos conhecimentos obtidos na academia pode proporcionar oportunidades profissionais aos acadêmicos, se existir uma melhor forma de monitoramento, integrando instituiçōes de ensino e empresas.

PALAVRAS-CHAVE: Gestão de conhecimento. Estágios. Ensino versus aprendizagem.

\section{Abstract}

The interaction enters the knowledge management and the periods of training, take to an evaluation of the procedures adopted for the companies concessors. The trainees in turn, wait to get benefits of education and learning, as well as economic.

This last one is most of the time for subsidizing the decurrent expenditures of its permanence in the university. However, when they initiate so longed for stage of period of training, normally to apartir of $5^{a}$ phase, if they come across with a reality not waited. Some are used as substitute of other employees, serving as well as "cheap man power" for not the incidence of the social changes. It is notified, however, that the application of the knowledge gotten in the academy can provide professional chances to the academics, if to exist one better form of monitoramento, integrating institutions of education and companies.

KEYWORDS: Management of knowledge. Periods of training. Education $\times$ learning

Este artigo foi apresentado no VIII SEMEAD - Seminários em Administraçāo, realizado nos dias 11 e 12 de agosto de 2005, na Universidade de São Paulo. 
Elisete Dahmer Pfischer; Joisse Antônnio Lorardi; Sérgio Marian; Letícia Fátima Nascimento; Paulo César Pfischer; Michely Nascimento;

\section{INTRODUÇÃO}

A tendência do crescimento de estágios aumenta cada vez mais. Algumas empresas apostam nos universitários para serem trejnados a fim de ocuparem posições estratégicas dentro de suas instituições. Outras infelizmente não têm esta mesma visão e utilizam seus estagiários como "mão-de-obra barata". Isso decorre pelas baixas bolsas auxílio e principalmente pela não incidência dos encargos sociais.

As perspectivas de ensino versus aprendizagem, através dos estágios, necessitam ser analisadas. Segundo Barreto (2004, p.1), a outra prática relativa a estagiários considerada eficaz é o chamado "Programa Sombra [...]". O acadêmico acompanha o presidente da empresa em todos os seus compromissos e reuniões. No final do período de trabalho as decisões são realizadas em conjunto.

A gestão do conhecimento, advinda do estágio realizado com sucesso, pode garantir uma empregabilidade futura aos acadêmicos. Os termos de compromissos, os programas de atividades e relatórios de estágios, podem ser cuidadosamente verificados a fim de não desvirtuarem as funções desta atividade pedagógica. Assim, este artigo é baseado em uma pesquisa realizada nos relatórios de estágios do curso de Ciências Contábeis. E tem como objetivo verificar se os estágios são fontes de conhecimento ou de mão-de-obra menos onerosa.

\section{A GESTÃO DO CONHECIMENTO E A INFORMAÇÃO}

Numa universidade ou empresa, a gestão do conhecimento é o que determina os caminhos e objetivos a serem atingidos. Evidentemente numa universidade este fator é a finalidade do processo de aprendizagem, mas no ambiente empresarial, cujo fim é outro, a gestão do conhecimento torna-se uma ferramen- ta de diferencial frente ao mercado, para sua sobrevivência, através da otimização do seu capital intelectual.

Fleury e Oliveira Júnior (2001 apud Fernandes, 2002, p.15) compreendem por gestão do conhecimento "a tarefa de identificar, desenvolver, disseminar e atualizar o conhecimento estrategicamente relevante para a empresa seja por meio de processos internos, seja por meio de processos externos às empresas".

O capital humano surge, neste sentido, como a base estrutural, sendo então disseminado por toda a organização, conforme mostra a Fig. 1.

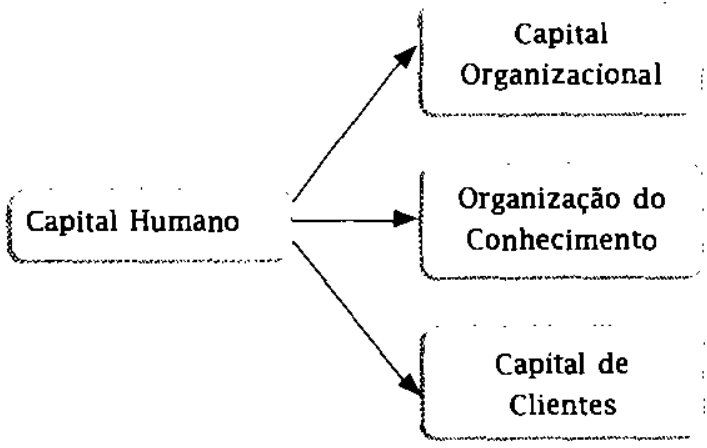

Figura 1 -Capital Humano dentro organização.

Fonte: (Santos, 2000).

Assim o estagiário envolvido na empresa consegue interagir, conhecendo a organização.

Considerando a importância da gestão do conhecimento nas empresas, a proximidade entre os acadêmicos que estagiam no sentido de agregar valor a essas empresas e a visão da universidade sobre um dado assunto teóricocientífico enriquece os envolvidos, acadêmicos, empresas e universidade, através do compartilhamento de conhecimentos.

Conforme Fernandes (2002, p.112), "a relação simbiótica entre escola que alimenta a empresa e a empresa adentrando a escola disponibiliza recursos para melhorar a qualidade" faz com que a interação entre universida- 
de e empresa se fortaleça. Saindo do mundo teórico das idéias, a universidade transporta seus conhecimentos para o meio externo, através dos acadêmicos que estagiam, havendo assim uma interaçăo entre acadêmicos e empresas.

Embora os acadêmicos, algumas vezes estagiem nas empresas e ofereçam contribuição significativa, os gestores não conseguem manter e reter seus conhecimentos. Por isso a importância do papel da gestão do conhecimento, fundamentada numa rede de coleta de dados e análise das informaçōes, desenvolve um processo de aprendizagem, dentro da empresa.

Outro fator a ser observado, é que a empresa presa a sua rotina diária pode não perceber os novos conhecimentos que estão surgindo. Para transpor essa barreira da cultura organizacional, os acadêmicos, muitas vezes, se tornam a ponte de interação entre o conhecimento teórico (universidade) e prático (empresas), podendo ocorrer processo inverso, isto é, as empresas, desenvolvendo novos métodos decorrentes das suas atividades e experiência, podem desenvolver e aplicar novas teorias, fazendo com que o estágio se caracterize como uma atividade de pesquisa em essência.

Através das visitas dos professores nas empresas, com a finalidade de supervisionar os estágios, ocorre o fortalecimento da relação universidade-empresa. Assim, para melhor entender a realidade na qual as empresas estão inseridas, professores e acadêmicos podem desenvolver projetos de pesquisa e extensão estreitando o laço entre conhecimento teórico-prático.

Concordando com Fernandes (2002, p.122) "a cooperação universidade-empresa foi vista como um processo importante de articulação e inserção na sociedade do conhecimento, considerando uma vantagem estratégica e poder vivenciar por meio desse processo e realidade empresarial".

Toda essa experiência proporciona aos acadêmicos crescimento profissional e vínculo com o meio empresarial. Ocorre, deste modo, um enriquecimento das experiências práticas adquiridas nas empresas e do conhecimento adquirido na universidade.

\section{VANTAGENS DO ESTÁGIO}

Dentre as vantagens podem ser citadas as seguintes, não necessariamente nesta ordem de importância, pois este fator depende dos objetivos de cada empresa. Porém, certamente todas, de alguma forma, irão influenciar na decisão da contratação de um estagiário.

\subsection{BAIXO CUSTO FINANCEIRO}

Este custo está relacionado principalmente a dois itens:

a) O valor pago a título de remuneração '! para os funcionários contratados pelo regime de CLT o salário está baixo. Entretanto para as empresas qualquer aumento é significativo, uma vez que os custos de maneira geral estão elevados, não somente pelo preço que se paga pela manutenção do software ou do cartucho de tinta para impressora, ou até mesmo do papel, mas principalmente pela quantia de obrigações a que as empresas de contabilidade estão sendo submetidas, não havendo mais como repassar para o produto ou serviço aqueles custos;

b) O valor dos encargos "! este item talvez seja mais relevante do que o primeiro em alguns casos. Os encargos, INSS e FGTS, representam um acréscimo em torno de $36 \%$ do salário pago aos funcionários. Entretanto, no contrato de um estagiário há somente o seguro mais a taxa, se for o caso, cobrada pela empresa que elabora o contrato. Existem ainda as férias, acrescidas de $1 / 3$, e o $13^{\circ}$ salário, cujos encargos também não estão presentes 
Elisete Dahmer Pfischer; Joisse Antônio Lorardi; Sérgio Marian; Letícia Fátima Nascimento; Paulo César Pfischer; Michely Nascimento;

no contrato de estágio.

Este custo financeiro pode ser melhor evidenciado ao se verificar valores, podendo ser constatado que o estagiário representa $50 \%$ a menos do que o custo do funcionário em regime de CLT:

\begin{tabular}{|c|c|c|c|c|c|}
\hline \multicolumn{3}{|c|}{ Estagiário } & \multicolumn{3}{|c|}{ Funciontrio CIT } \\
\hline 1 & Remuneração & 400,00 & 1 & Remuneração & 520,00 \\
\hline 2 & Adicional & 40,00 & 2 & Férias $+1 / 3$ & 57,77 \\
\hline \multicolumn{2}{|c|}{ Subtotal $(1+2)$} & 440,00 & 3 & $13^{\circ}$ salário & 43,33 \\
\hline & & & \multicolumn{2}{|c|}{ Subtotal $(1+2+3)$} & 621,10 \\
\hline & & & 4 & INSS (28\%) & 173,91 \\
\hline & & & 5 & FGTS $(8,5 \%)$ & 52,79 \\
\hline & & & \multicolumn{2}{|c|}{ Subtotal $(4+5)$} & 226,70 \\
\hline \multicolumn{2}{|c|}{ Total } & 440,00 & \multicolumn{2}{|c|}{ Total } & 847,80 \\
\hline \multicolumn{2}{|c|}{ Horas trabalhadas (6h) dia) } & 180,00 & \multicolumn{2}{|c|}{ Horas trabalhadas (comercial) } & 220,00 \\
\hline \multicolumn{2}{|c|}{ Valor por hora } & 2,44 & \multicolumn{2}{|c|}{ Valor por hora } & 3,85 \\
\hline
\end{tabular}

Figura 2 - Comparativo do custo de um funcionário e de um estagiário

\subsection{INTERESSE DO ESTAGIÁRIO EM PROGREDIR}

Este fator é apreciado por algumas empresas, pois o interesse do estagiário em aprender a fazer e conseqüentemente a melhorar o trabalho é algo que não é encontrado com tanta facilidade nos empregados, que muitas vezes já estão desmotivados, por razões que não vem ao caso elencar. Entretanto algumas podem estar relacionadas inclusive com a filosofia de trabalho da empresa e, desta forma, alguém recém-chegado, sem ter ligação, e com interesse, é muito bem-vindo.

\subsection{MĀO-DE-OBRA RELATIVAMENTE QUALIFICADA}

Considerando que o custo de um estagiário, conforme demonstrado, é menor, este item se torna ainda mais relevante. Um estagiário, mesmo que esteja no início do curso já tem alguma noção de contabilidade, bem como certamente domina recursos de informática. Desta forma torna-se alguém de vital importância para a empresa.

\section{O ESTÁGIO COMO FORMAÇÃO ACADÊMICA NO ENSINO E APRENDIZAGEM}

O estágio é regido por legislação específica, pela Lei 6.494, de 7 de dezembro de 1977 , regulamentada pelo Decreto 87.497 , de 18 de agosto de 1982 . Declara em seu Art. $1^{\circ}$ que deve ser desempenhado em unidades que tenham condiçōes de proporcionar experiência prática na linha de formação, devendo auxiliar na complementaçào do ensino e da aprendizagem a serem planejados, executados, acompanhados e avaliados em conformidade com os currículos escolares. (BRAGA e GEJSEL, 1977)

Este procedimento didático-pedagógico possibilita aos estudantes aplicarem seus conhecimentos na prática e estabelece a oportunidade de introduzir o acadêmico no ambiente profissional, para o desenvolvimento das atitudes e posturas exigidas no mercado de trabalho, como: a criatividade, a responsabilidade, o senso crítico, a organização. 
Para a empresa concedente do estágio as vantagens são muitas, desde a ação social a colaboradores, que possuem conhecimento teórico e potencial intelectual, capacitados para atender às necessidades da empresa. No âmbito econômico é concedido o direito de estipular o valor da bolsa-auxílio, para subsidiar o estagiário em suas despesas escolares, transportes, alimentação e vestuário. Outra vantagem é o fato da empresa poder posteriormente lançar estes gastos, desde que previstos em lei, como despesa operacional, reduzindo assim o lucro.

$\mathrm{Na}$ instituição de ensino há a complementação do processo de aprendizagem do futuro profissional, porque no confronto da teoria com a prática o conhecimento é absorvido. A interação do aluno $x$ empresa $x$ vida acadêmica forma uma dinâmica no processo educativo, fazendo com que ele sempre fique atualizado e sintonizado com as mudanças.

O estágio, na sua essência, deve ser visto como uma atividade de pesquisa e extensão, de vivenciar o conhecimento teórico. Como diz o navegador Amyr Klink (2000), um homem precisa viajar por sua conta, não por meio de histórias, imagens, livros ou TV. Precisa viajar por si, com seus olhos e pés, para entender o que é seu. Para um dia plantar suas próprias árvores e dar-lhes valor. Conhecer o frio para desfrutar do calor. E o oposto. Sentir a distância e o desalento para estar bem sob o próprio teto. Um homem precisa viajar para lugares que não conhece para quebrar essa arrogância que nos faz ver o mundo como imaginamos, e não como é realmente.

$E$ interessante ao aluno esse amadurecimento, no qual ele vá lá e confira como as coisas funcionam, pois, a partir desse momento, ele estará aprendendo realmente. Ressalta-se que a vivência acadêmica é importante, mas só será útil se puder ser aplicada em situações reais.

Porém, algumas empresas, órgãos públicos e instituições de ensino estão desvirtuando o estágio de sua real aplicação, que ế a de proporcionar ao estagiário a conciliação entre a aprendizagem didática e a profissional. Infelizmente estāo recrutando estudantes para desempenharem atividades não relacionadas com sua a área de formação, utilizando-os como uma "mão-de-obra barata".

Esta desvirtuação ocorre porque os benefícios econômicos em se contratar estagiários são muitos, pois a atividade de estágio tem sua regulamentação própria, não é regida pela CLT (Consolidação das Leis do Trabalho), proporcionando à empresa o não pagamento de obrigações como contribuição sindical, verbas rescisórias, recolhimento do INSS (Instituto Nacional de Seguridade Social) e do FGTS (Fundo de garantia por Tempo de Serviço), bem como o não pagamento de férias e $13^{\circ}$ salário.

No entanto, cabe principalmente ao estudante a responsabilidade de antes de começar a estagiar, avaliar se as funçōes propostas pela empresa condizem com o seu currículo de graduação. Só assim a atividade lhe renderá maior proveito, ampliando seus conhecimentos e servindo de complemento das informações fornecidas nos bancos acadêmicos.

$A$ responsabilidade recai também sobre a instituição de ensino, como gestora do processo estagiário, e a empresa. Esta deve regulamentar e fiscalizar a atividade, verificando se estão sendo atingidos os benefícios propostos.

Numa pesquisa preliminar junto à coordenadoria de estágio do curso de Ciências Contábeis da Universidade Federal de Santa Catarina, verifica-se que $70 \%$ dos relatórios de estágio apresentam correlação entre a atividade desenvolvida no estágio e currículo de graduaçāo, conforme figura 3 . 
Elisete Dahmer Pfischer; Joisse Antônio Lorardi; Sèrgio Marian; Letícia Fátima Nascimento; Paulo César Pfischer; Michely Nascimento;

\begin{tabular}{|c|c|c|}
\hline Acadêmico & Empresa Estaglada & Atividades desenvolvidas \\
\hline A & Tribunal Regional Eleitoral de Santa Catarina & $\begin{array}{l}\text { Acompanhamento de índice de } \\
\text { crescimento económico nacional e } \\
\text { acompanhamento financeiro dos } \\
\text { pagamentos efetuados. }\end{array}$ \\
\hline B & Sensato Contabilidade e Comércio de Serviços Ltda & $\begin{array}{l}\text { Conferência de lançamentos } \\
\text { contábeis., atendimento ao público e } \\
\text { atendimento de telefone. }\end{array}$ \\
\hline $\mathrm{C}$ & Farmácia e Drogaria Ganzo Ltda & $\begin{array}{l}\text { Alimentação do programa fiscal } \\
\text { (LISCAL) e apuração de impostos }\end{array}$ \\
\hline D & Prefeitura Municipal de Florianópolis & $\begin{array}{l}\text { Conferência de materiais e serviços } \\
\text { prestados e reprogramação de fluxo } \\
\text { de caixa mensal. }\end{array}$ \\
\hline $\mathrm{E}$ & NAS - Serviços Contábeis L.tda & $\begin{array}{l}\text { Arquivamento de documentos e } \\
\text { Contabilidade. }\end{array}$ \\
\hline $\mathbf{F}$ & Banco do Brasil / Gerel & $\begin{array}{l}\text { Impressão de relatórios, confecçảo de } \\
\text { textos e planilhas e manutenção de } \\
\text { arquivos. }\end{array}$ \\
\hline G & MCA Assessoria Contábil & $\begin{array}{l}\text { Lançamentos contábeis, apuração de } \\
\text { impostos e atendimento ao público. }\end{array}$ \\
\hline H & Agência Catarinense de Fomento S/A & $\begin{array}{l}\text { Conciliação de controle de saldos } \\
\text { financeiros e informaçōes gerenciais. }\end{array}$ \\
\hline I & Justiça Federal & $\begin{array}{l}\text { Cálculo de margem consignável, } \\
\text { auxiliar nos lançamentos da folha de } \\
\text { pagamento e efetuar atividades } \\
\text { administrativas. }\end{array}$ \\
\hline$J$ & Empresa Brasileira de Correios e Telégrafos - DR/SC & $\begin{array}{l}\text { Conciliaçào de conta de movimento } \\
\text { das agências e efetuar serviços } \\
\text { auxiliares. }\end{array}$ \\
\hline
\end{tabular}

Figura 3 - Correlação atividade de ensino e estágio do Curso de Ciências Contábeis. Fonte: (dados pesquisados).

É constatado, com base na figura 1, que o estágio está sendo desempenhado, porém não totalmente em sua função didático-pedagógica. A maioria dos acadêmicos realiza funçōes correlacionadas com a área de formação e os 30\% restantes: os estagiários D, F e J afirmam que a correlação é pouca, mas existente. No entanto, o que preocupa é a existência, em alguns casos, de atividades administrativas no cotidiano do estagiário como: atender telefone, arquivar documentos e atender ao público.

Para evitar que esta situação continue ocorrendo, cabe à instituição de ensino, em conjunto com o aluno, adotar medidas corretivas para o estágio não causar "efeito substituição", onde o empregado é dispensado e substituído por estagiário. Além disso, quando os alunos desempenham essas funçōes coadjuvan- 
- Estágio como fonte de conhecimento ou mão-de-obra menos onerosa?

tes estão prejudicando diretamente a entrada de muitos jovens, recentemente formados no $2^{\circ}$ grau, no mercado de trabalho.

O estágio quando exercido corretamente, contribui de maneira considerável para a formação de futuros profissionais, ressaltando a viabilidade quanto aos conhecimentos adquiridos, conforme comprova a figura 4 .

\begin{tabular}{|c|c|c|}
\hline Acadêmico & Empresa estagiada & Conhecimentos adquiridos \\
\hline A & Tribunal Regional Eleitoral de Santa Catarina & $\begin{array}{l}\text { Na área da administração pública, } \\
\text { visto que não se tem muito contato } \\
\text { durante a graduação. }\end{array}$ \\
\hline B & Sensato Contabilidade e Comércio de Serviços Ltda & $\begin{array}{l}\text { A aprendizagem é gradativa, } \\
\text { auxiliando no entendimento das } \\
\text { disciplinas não muito vistas em aula. }\end{array}$ \\
\hline $\mathrm{C}$ & Farmácia e Drogaria Ganzo Ltda & $\begin{array}{l}\text { Conciliação teórica com a prática e } \\
\text { aplicação das normas vigentes. }\end{array}$ \\
\hline $\mathrm{D}$ & Prefeitura Municipal de Florianópolis & $\begin{array}{l}0 \text { aprendizado é muito, pois pouca } \\
\text { coisa tinha visto em aula. }\end{array}$ \\
\hline $\mathbf{E}$ & NAS - Serviços Contábeis Ltda & $\begin{array}{l}\text { o conhecimento adquirido é } \\
\text { bastante, pois os lançamentos } \\
\text { contábeis na prática são muito } \\
\text { complexos e variados. }\end{array}$ \\
\hline $\mathrm{F}$ & Banco do Brasil / Gerel & Responsabilidade. \\
\hline G & MCA Assessoria Contábil & $\begin{array}{l}\text { O conhecimento está relacionado } \\
\text { com o desenvolvimento de } \\
\text { experiência profissional na área de } \\
\text { formação, pois permite aplicar os } \\
\text { conhecimentos didáticos na prática. }\end{array}$ \\
\hline $\mathrm{H}$ & Agência Catarinense de Fomento S/A & $\begin{array}{l}\text { Conciliação da teoria com a prática e } \\
\text { contato com documentos diversos. }\end{array}$ \\
\hline I & Justiça Federal & $\begin{array}{l}\text { Desenvolvimento do relacionamento } \\
\text { interpessoal no ambiente de trabalho. }\end{array}$ \\
\hline J & Empresa Brasileira de Correios e Telégrafos - DR/SC & $\begin{array}{l}\text { Contato com o público e o } \\
\text { relacionamento com os profissionais. }\end{array}$ \\
\hline
\end{tabular}

Figura 4 - Conhecimentos adquiridos pelos estagiários do curso de Ciências Contábeis. Fonte: (dados pesquisados).

Os dados apresentados comprovam que o estágio é uma ferramenta importante para complementar a formaçăo acadêmica. Dos 10 (dez) estudantes analisados na figura 2, 40\% declaram que esta atividade extracurricular lhes propiciou conhecimento de disciplinas pouco abordadas na grade escolar e $30 \%$ que auxiliou na conciliação teoria e prática. Para $30 \%$ dos estagiários a contribuição não está associada com a área de formação, mas sim com atividades diversas.

Portanto, para melhor aproveitar os bene- 
fícios concedidos por esta atividade pedagógica, é fundamental que o aluno tenha delimitado qual seu objetivo futuro e qual o ramo da profissão pretende seguir. Ainda necessita analisar se a entidade concedente lhe fornecerá uma aprendizagem adicional na área de formação desejada, suprindo suas perspectivas profissionais.

\section{CONCLUSÕES E RECOMENDAÇÕES}

A união da teoria com a prática vem, muitas vezes, dos estágios realizados nas empresas conscientes da valorização do acadêmico como um futuro profissional.

Os freqüentadores dos bancos escolares das universidades são recrutados pelas empresas, para prestação de serviços tanto no setor público como no privado, do mercado de trabalho.

Esses processos, às vezes, são desvirtuados em decorrência da falta de uma legislação clara e também da falta de fiscalização dos órgãos competentes. Isso faz com que o estágio, desempenhado em unidades que tenham condições de proporcionar novas experiências profissionais, venha sendo utilizado como mão-de-obra menos onerosa. Desta forma, essas organizações aumentam seus lucros e enfraquecem as oportunidades de emprego.

As pesquisas recentemente realizadas, junto aos estagiários, refletem esta preocupação, uma vez que o estágio atinge um percentual de $70 \%$ dos objetivos pedagógicos, propostos no termo de compromisso de estágio, que é o auxilio à complementação do ensino e aprendizagem.

Em outra questāo abordada, somente $30 \%$ declaram haver compatibilidade com as disciplinas oferecidas no curso, $40 \%$ mostram a relevância do estágio quanto às disciplinas pouco abordadas na grade curricular. Os outros $30 \%$ declaram não haver contribuição no âmbito de formação.

Entretanto, acredita-se que o estágio quando empregado e monitorado de maneira correta, contribui significativamente para a futura formação do profissional. Necessita-se, portanto, de um acompanhamento mais aprofundado para que os estagiários sejam profissionais competentes, ocupando posições estratégicas nas empresas, e efetivamente líderes no futuro.

\section{REFERÊNCIAS BIBLIOGRÁFICAS}

BARRETO, Thiene.Universitários sāo treinados para ocupar posições estratégicas nas companhias. São Paulo, Jornal do comércio, 2004.

BRAGA, Ney; GEISEL, Ernesto. Legislação especifica sobre estágio. Brasilia, Diário Oficial, 1977.

KLINK, Amyr. Mar sem fim. São Paulo: Companhia das Letras, 2000.

PIETROVSKI, Eliane Fernandes. A gestāo do conhecimento e a cooperação universidade - empresa: o caso da Unidade de Ponta Grossa do Cefet-Pr. Dissertaçăo (Mestrado) - Pós-Graduaçăo em Engenharia de Produção, Universidade Federal de Santa Catarina, Florianópolis, p.15-112.

SANTOS, Neri dos Santos. Inteligència Competitiva. Pós-Graduação em Engenharia de Produção, Universidade Federal de Santa Catarina, Florianópolis, 2000. 